\title{
Christine Wilke
}

\section{Die Adoption minderjähriger Kinder durch den Stiefelternteil}

\author{
Vergleichende Analyse des deutschen und englischen Rechts
}

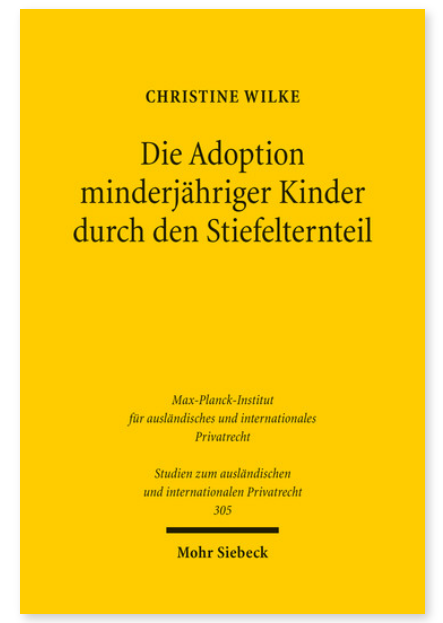

2014. XXII, 352 Seiten. StudIPR 305

ISBN 978-3-16-152862-0

DOI 10.1628/978-3-16-152862-0

eBook PDF $89,00 €$

ISBN 978-3-16-152818-7

fadengeheftete Broschur $89,00 €$
Stiefkindadoptionen, die heutzutage mehr als die Hälfte aller jährlich beschlossenen Minderjährigenadoptionen in Deutschland ausmachen, stehen in einem Spannungsverhältnis zum Leitbild des Adoptionsrechts und sind nach sozialwissenschaftlichen Untersuchungen nicht selten problembelastet. Christine Wilke untersucht die Rechtsposition und Interessenlage der an einer solchen Adoption primär Beteiligten - Stiefelternteil, Stiefkind und außenstehender leiblicher Elternteil - unter Berücksichtigung psychosozialwissenschaftlicher Erkenntnisse und gesellschaftspolitischer Erwägungen. Vergleichend zieht sie hierbei die Rechtslage und Praxis in England heran, wo die intensive rechtspolitische Diskussion dieser Problematik bereits in den 70er Jahren gesetzgeberische Reaktionen nach sich gezogen hat. Basierend auf den aus dem Rechtsvergleich gewonnenen Erkenntnissen nimmt sie Stellung zu Lösungansätzen im Recht der Stieffamilie sowie im Adoptionsrecht.

Christine Wilke Geboren 1982; Studium der Rechtswissenschaften und wissenschaftliche Mitarbeit an der Albert-LudwigsUniversität Freiburg; Rechtsreferendariat am Landgericht Köln; 2012 Promotion; 2013 Zweite Juristische Staatsprüfung.

\section{Jetzt bestellen:}

https://mohrsiebeck.com/buch/die-adoption-minderjaehriger-kinder-durch-den-stiefelternteil-9783161528620?no_cache=1 order@mohrsiebeck.com

Telefon: $+49(0) 7071-923-17$

Telefax: $+49(0) 7071-51104$ 